(C2019, Elsevier. Licensed under the Creative Commons Attribution-NonCommercialNoDerivatives 4.0 International http://creativecommons.org/about/downloads

(c) $($ ) $(9)$ 


\title{
Effect of Strain Rate on Deformation Behavior of Aluminum Matrix Composites with $\mathrm{Al}_{2} \mathrm{O}_{3}$ Nanoparticles
}

\author{
Z. Zaiemyekeh ${ }^{\mathrm{a}}$, G. H. Liaghat ${ }^{\mathrm{a}, \mathrm{b}}$, H. Ahmadi ${ }^{\mathrm{a}}$, M. K. Khan ${ }^{\mathrm{c}, \mathrm{d}}$, O. Razmkhah ${ }^{\mathrm{c}}$ \\ ${ }^{a}$ Department of Mechanical Engineering, Tarbiat Modares University, Tehran, Iran \\ ${ }^{b}$ School of Mechanical \& Aerospace Engineering, Kingston University, London UK \\ ${ }^{c}$ Institute of Future Transport and Cities, Coventry University, Coventry, CV1 5FB, UK \\ ${ }^{d}$ Department of Mechanical Engineering, DHA Suffa University, Karachi, Pakistan \\ Email: zahrazaiem@modares.ac.ir \\ Corresponding author: GHLIA530@modares.ac.ir, Gholamhossein.Liaghat@kingston.ac.uk
}

\begin{abstract}
This study aims to investigate the quasi-static and high strain rate deformation of an aluminumbased metal matrix composite reinforced with $\mathrm{Al}_{2} \mathrm{O}_{3}$ nanoparticles. The addition of $\mathrm{Al}_{2} \mathrm{O}_{3}$ nanoparticles with an optimal weight percentage increased the strength and energy absorption capacity of the composite material. The deformation characteristics of the material were found to be strain rate sensitive. It was concluded that the usage of an optimal weight percentage of nanoparticles results in a markedly higher energy absorption capacity in a variety of strain rates of deformation. Moreover, the energy absorption capacity of the present metal matrix composites increased significantly at the higher strain rates of deformation. It was found that the excessive addition of nanoparticles to the metal matrix decreases the energy absorption capacity as well as strain rate sensitivity of the composite material.
\end{abstract}

Keywords: Metal Matrix Composites, $\mathrm{Al}_{2} \mathrm{O}_{3}$ Nanoparticles, Mechanical Properties, High Strain Rate, Energy Absorption Capacity

\section{Introduction}

The use of metal matrix composites (MMCs) is continuously increasing in engineering applications. The addition of high strength nanoparticles in suitable parent matrix increases the strength, wear, toughness, and energy absorption capacity of the material [1-2]. The low density materials like aluminum, magnesium, and titanium are generally reinforced with nanoparticles to develop the MMCs. Aluminum and its alloys are widely used in engineering applications. Their low density and higher elongation at failure make them materials of choice in light weight components in aerospace, automobile, and locomotive. However, aluminum and its alloys show very low strain hardening in plastic deformation and perform poorly in fretting, wear, impact, and energy absorption applications [1, 3].

The nanoparticles of boron carbide, silicon carbide, and aluminum oxide form a very homogenous bonding with aluminum [4-5]. The combination of the superior ductility of aluminum and reinforcement of ceramic develop an attractive engineering material for high strength, hardness, and wear resistant applications [5-7]. However, there are several engineering challenges in the use of aluminum-based MMCs in engineering applications. The 
consistent material properties of MMCs are perceived as the most important criteria for their qualification. The uniform and homogenous distribution of nanoparticles is a prerequisite for consistent deformation behavior and performance of the MMCs. The uniform distribution of nanometer size particles in the bulk matrix is extremely challenging [5, 8-10]. The addition of a lower weight percentage of nanoparticles does not adequately manipulate the material properties of MMCs. Similarly, the undue weight percentage of the nanoparticles adds brittleness and agglomeration to the material. The optimal weight percentage of the nanoparticles that produces the anticipated material properties varies with the type of matrix, size of nanoparticles, and elastic-plastic properties of matrix and nanoparticles.

The optimal weight percentage of nanoparticles in MMCs is obtained from the mechanical properties testing, which has been investigated in the literature. Rahimian et al. [11] investigated the effects of particle size of Al2O3 in an aluminum matrix and observed a higher increase in hardness, yield strength, and elongation to fracture for smaller size nanoparticles. Christman et al. [12], Liu et al. [13], and Yang et al. [14] used SiC nanoparticles for strengthening aluminum matrix and observed higher compressive strength and ductility of the material. Nan et al. [15] used dislocation plasticity to investigate the effects of particle size, distribution, and volume fraction on the deformation behavior of an aluminum matrix reinforced with SiC nanoparticles. They concluded that the strength of MMCs is mainly controlled by the particle cracking phenomenon in loading. Chen et al. [16] and Kok [17] investigated the effects of particle size and weight fractions on the strength of the metal matrix composites. The previous studies on the aluminum-based metal matrix composites concentrated on static loading mode to investigate the characteristics of the material. The positive effect of the addition of nanoparticles on the hardness and compressive strength of the MMCs have been confirmed in [12].

The markedly higher strain at fracture for MMCs has been ignored in the past. The plateau stress in quasi-static deformation of MMCs enables a significant amount of energy absorption up to fracture. This attribute of MMCs can be extremely useful in applications related to impact and crash, where materials with high energy absorption capacity are required for safe operation. The strain rate in deformation affects the material properties and performance of the materials. The variation in material properties of MMCs with strain rates has been investigated in very few studies [18-24]. The high strain rate deformation characteristics of materials are investigated with Split Hopkinson Pressure Bar (SHPB) testing at various strain rates. Harding et al. [18] and Yadav et al. [19], in their separate studies, investigated the variation in the dynamic behavior of $\mathrm{SiC}$ reinforced aluminum with strain rates up to $10^{3} \mathrm{~s}^{-1}$. Chichili et al. [20] found that the deformation in $\mathrm{Al} 6061$ with alumina nanoparticles varies with high strain rate. Marchi et al. [21] observed the variation in deformation characteristics of an aluminum matrix based MMCs reinforced with $\mathrm{Al}_{2} \mathrm{O}_{3}$ nanoparticles with strain rates. They observed particle cracking led to deformation of MMCs followed by matrix cavitation and found higher strain rate sensitivity in MMCs with the higher weight percentage of nanoparticles. Shen et al. [22] investigated the variation in deformation behavior of an $\mathrm{Mg}$ matrix reinforced with SiC nanoparticles with strain rates. They also observed variation in deformation behavior of metal matrix composites with a weight percentage of nanoparticles. Xiao et al. [23] and Chen et al. [24] in their separate studies observed higher compressive strength, ductility, and energy 
absorption capacity of SiC reinforced $\mathrm{Mg}$ composites at higher strain rates. These studies revealed that the deformation mechanism of metal matrix composites varies noticeably at higher strain rates. However, the understanding of variation in deformation mechanism of MMCs at different strain rates is still empirical and there is no mathematical model for prediction of the material properties of MMCs with variation in strain rate of deformation. Hence, case-by-case experimental investigations were carried out on various specimens to determine the compressive strength and fracture strain of the composite system.

This study investigates the quasi-static and dynamic behavior of $\mathrm{Al}_{2} \mathrm{O}_{3}$ reinforced aluminum composites. The nanocomposite specimens were fabricated with powder metallurgy with different weight percentages of nanoparticles. The deformation mechanisms at low and high strain rates were investigated. The specimens with an optimal weight percentage of nanoparticles were found to have higher energy absorption capacity in static and dynamic loading. The results suggest that the $\mathrm{Al}_{2} \mathrm{O}_{3}$ reinforced MMCs can be advantageous in large deformation and high energy absorption applications. The results of this study provide information about the deformation mechanisms in low and high strain rate loading, which will be used in a broader study to develop a method for predicting the material properties of MMCs with various matrix types, weight percentages of nanoparticles, and strain rates of deformation in loading.

\section{Materials and experimental procedures}

\section{1- Materials and fabrication}

In this study, aluminum powder of $\sim 20 \mu \mathrm{m}$ particle size matrix was used with $20 \mathrm{~nm} \mathrm{Al}_{2} \mathrm{O}_{3}$ reinforcement. The chemical compositions of matrix and reinforcement are shown in Table 1. The MMCs are typically produced with casting and powder metallurgy methods. This study uses samples fabricated by powder metallurgy method, which culminates in uniform distribution of nanoparticles in the MMCs [9, 10]. The specimens with various weight percentages of nanoparticles ranging from 2.5 to $12.5 \mathrm{Wt}$. \% were manufactured. The matrix and reinforcement were initially mixed for $30 \mathrm{~min}$ at $2000 \mathrm{rpm}$. The mixture was then cold pressed in a cylindrical die at $\sim 600 \mathrm{MPa}$ pressure for one minute at room temperature. Zinc stearate was used as a lubricant to reduce the friction between the die wall and the punch. The compact blocks of the material sintered initially in argon atmosphere for $30 \mathrm{~min}$ at $620^{\circ} \mathrm{C}$ and then were kept in the vacuum for $60 \mathrm{~min}$ at the aforementioned temperature. The density of the specimens was found to be in the range of $94.5 \%$ to $99 \%$.

Table 1- Chemical analysis of matrix and nanoparticles used in the composite

\begin{tabular}{|c|c|c|c|}
\hline S. No. & Materials & Size & Element Weight (\%) \\
\hline 1 & Aluminum Powder & $20 \mu \mathrm{m}$ & $\mathrm{Al}$ 98.5, Na 0.5, Cu 0.35 \\
\hline 2 & $\mathrm{Al}_{2} \mathrm{O}_{3}$ Nanoparticles & $20 \mathrm{~nm}$ & $\mathrm{Al} 28.4, \mathrm{O}$ 66.8, N 3.7, Na 1.2 \\
\hline
\end{tabular}




\section{2- Quasi-static compression tests}

Quasi-static compression tests were conducted at room temperature on the cylindrical-shaped specimens with the same diameter and length of $15 \mathrm{~mm}$. The ASTM-E9 standard was used for the dimensions of specimen as well as compression testing parameters. The surfaces of the specimens were carefully polished to avoid any misalignment in the compression tests. The specimens were compressed at a strain rate of $10^{-3} \mathrm{~s}^{-1}$ corresponding to a $9 \mathrm{~mm} / \mathrm{min}$ crosshead speed. Fig. 1 shows the specimen used in compression. Three compression tests were carried out on each specimen category (i.e. based on the weight fraction of nanoparticles) and mean values of the material properties were used for analysis.

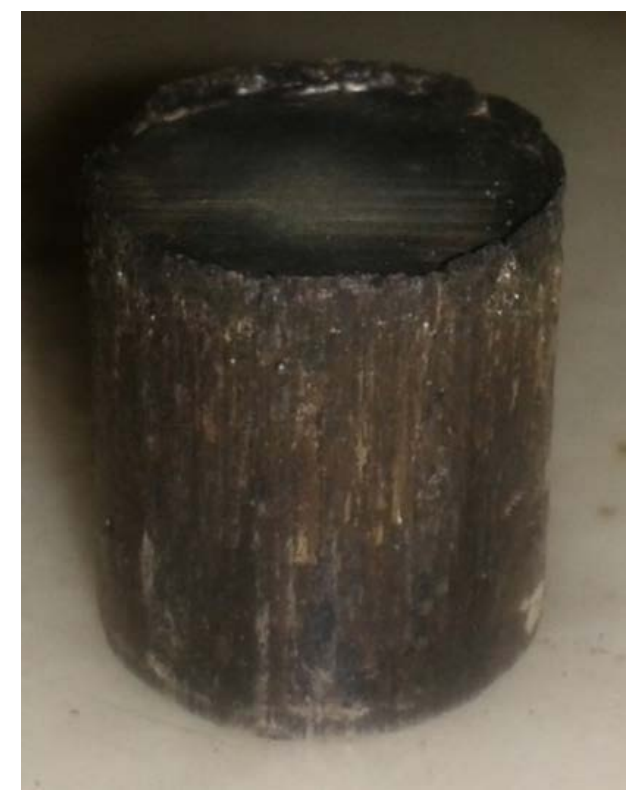

Fig. 1- Specimen used in the study

\section{3- Split Hopkinson Pressure Bar (SHPB) test}

The Split Hopkinson Pressure Bar (SHPB) test was used to study the high strain rate deformation characteristics of the material. The SHPB system works on the principle of dimensional wave propagation where a specimen is compressed between two high strength incident and transmission bars [25-27]. A striker is released with high velocity by releasing the pressurized gas. The striker impacts the input bar and generates a stress wave which partially transmits to the specimen and some part of the wave reflects back into the input bar until equilibrium is achieved. The specimen transmits the absorbed wave to the transmission bar. The wave signals are recorded by a multichannel oscilloscope using the strain gauges attached to the incident and transmission bars. The voltage output from wave signals is on the order of milli-volts. Therefore, a signal amplifier is used to accurately record the low-amplitude voltage. Fig. 2 shows the schematic of the SHPB test setup.

The dimensions of the specimen for SHPB tests were similar to those used in the static compression tests. The strain rate of 700,1400 and $3000 \mathrm{~s}^{-1}$ were used to apply loading on the 
specimens. Three tests were carried out on each specimen category to ensure the reproducibility of the experimental results. The reflected and transmitted signals are used in the calculation of stress $\sigma_{S}(t)$, strain rate $\dot{\varepsilon_{S}}(t)$, and strain $\varepsilon_{(t)}$ using Eq (1) to (3).

$$
\begin{aligned}
& \sigma_{S}(t)=\frac{A_{0}^{2} E_{0}}{A_{s}^{2}} \varepsilon_{t}(t) \\
& \dot{\varepsilon}_{S}(t)=-\frac{2 C_{0}}{l_{s}} \varepsilon_{R}(t) \\
& \varepsilon_{(t)}=\int \dot{\varepsilon}(\tau) d \tau
\end{aligned}
$$

where $C_{0}=\sqrt{E / \rho}$ is the wave speed of the input bar, $l_{s}$ is the length of the specimen, $\varepsilon_{R}$ is the reflected strain signal, $\varepsilon_{(t)}$ is the transmitted signal, $E_{0}$ is the elastic modulus of the bars, $A_{0}$ and $A_{s}$ represent the cross sectional area of the output bar and specimen, respectively.

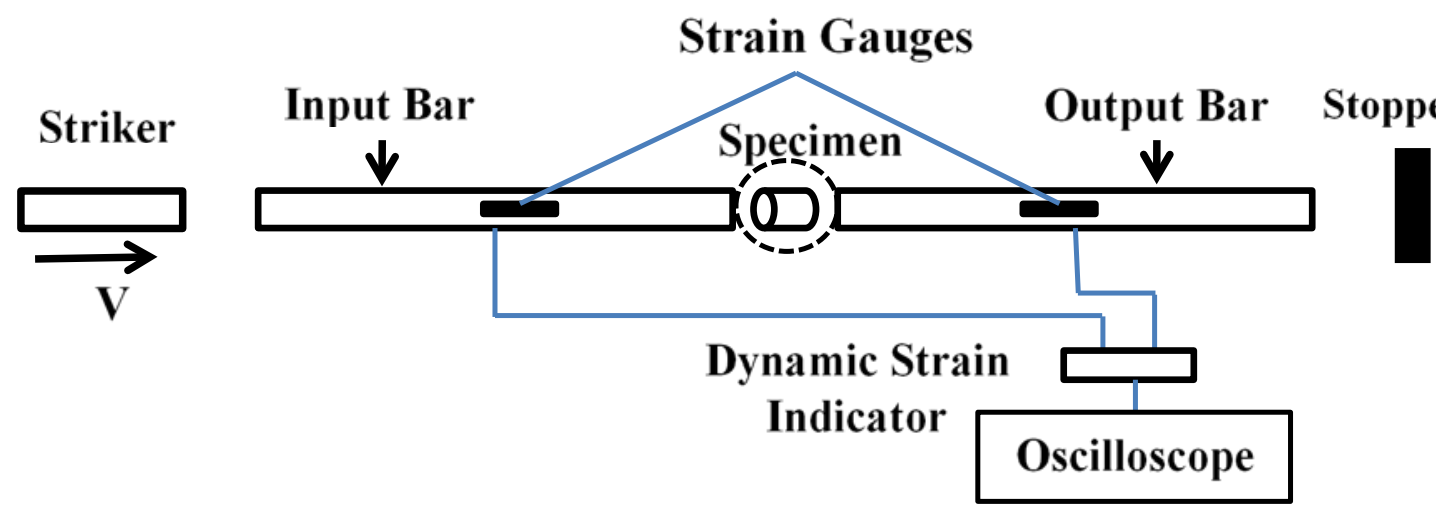

Fig. 2- Schematic representation of the SHPB test system

\section{Results and Discussions}

\section{1- Variation in the distribution of nanoparticles}

The distribution of the $\mathrm{Al}_{2} \mathrm{O}_{3}$ reinforcement particles in the aluminum matrix was investigated by Scanning Electron Microscope (SEM) and Energy Dispersive Spectrometry (EDS). Figs. 3 (a) and (b) show the uniform and homogenous dispersion of the $\mathrm{Al}_{2} \mathrm{O}_{3}$ nanoparticles in the composites. The homogenous distribution of the $\mathrm{Al}_{2} \mathrm{O}_{3}$ nanoparticles revealed the adequacy of the powder metallurgy process used for the fabrication of the specimens. Figs. 3 (c) and (d) show the dispersion of nanoparticles in the specimens with a higher weight percentage of $\mathrm{Al}_{2} \mathrm{O}_{3}$. It was found that the specimens have the agglomerations of $\mathrm{Al}_{2} \mathrm{O}_{3}$ in the matrix. The EDS examination of the material showed the composition of the material as aluminum and oxygen. Fig. 4 illustrates a typical EDS spectrum of the material. 


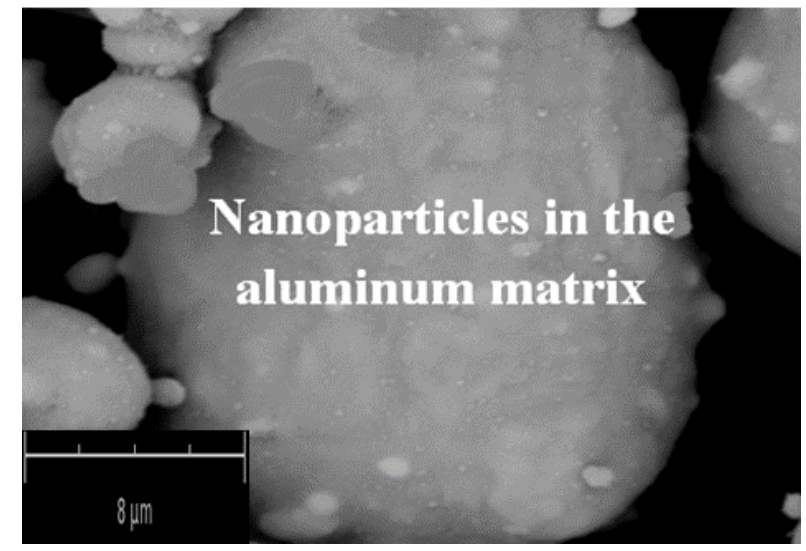

(a)

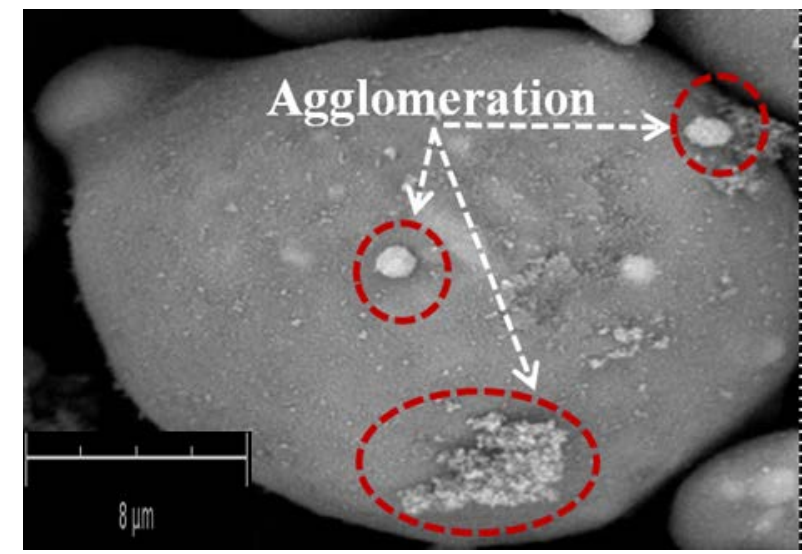

(c)

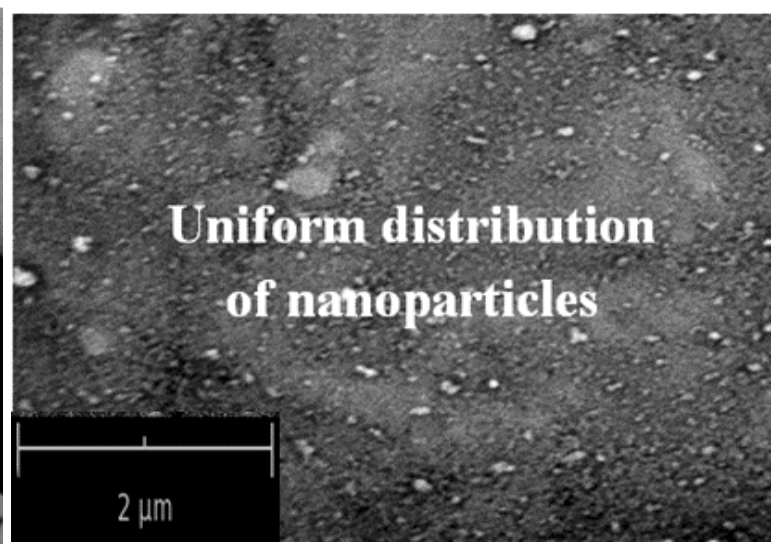

(b)

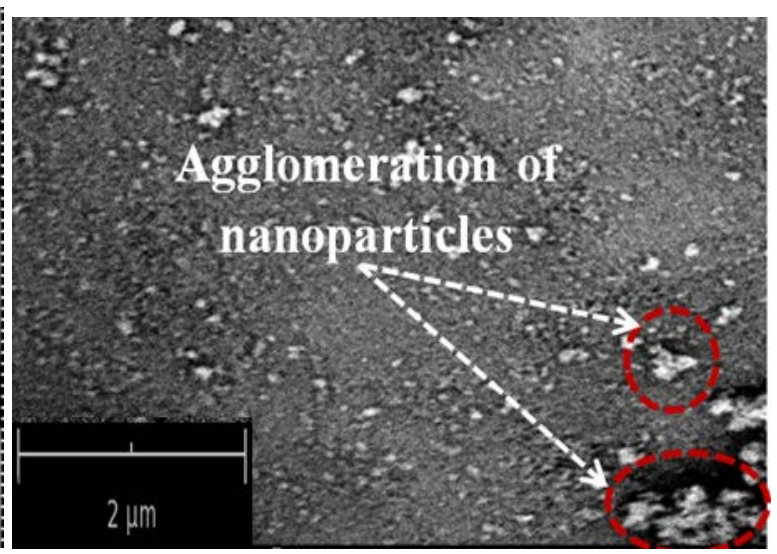

(d)

Fig. 3- SEM micrographs of mixed powders: (a) uniform dispersion of nanoparticles in the specimen with $2.5 \% \mathrm{Al}_{2} \mathrm{O}_{3}$, (b) high magnification image of the specimen shown in part (a) of the figure, (c) agglomeration of nanoparticles in the specimen with $12.5 \% \mathrm{Al}_{2} \mathrm{O}_{3}$, (d) high magnification image of the specimen shown in part (c) of the figure.

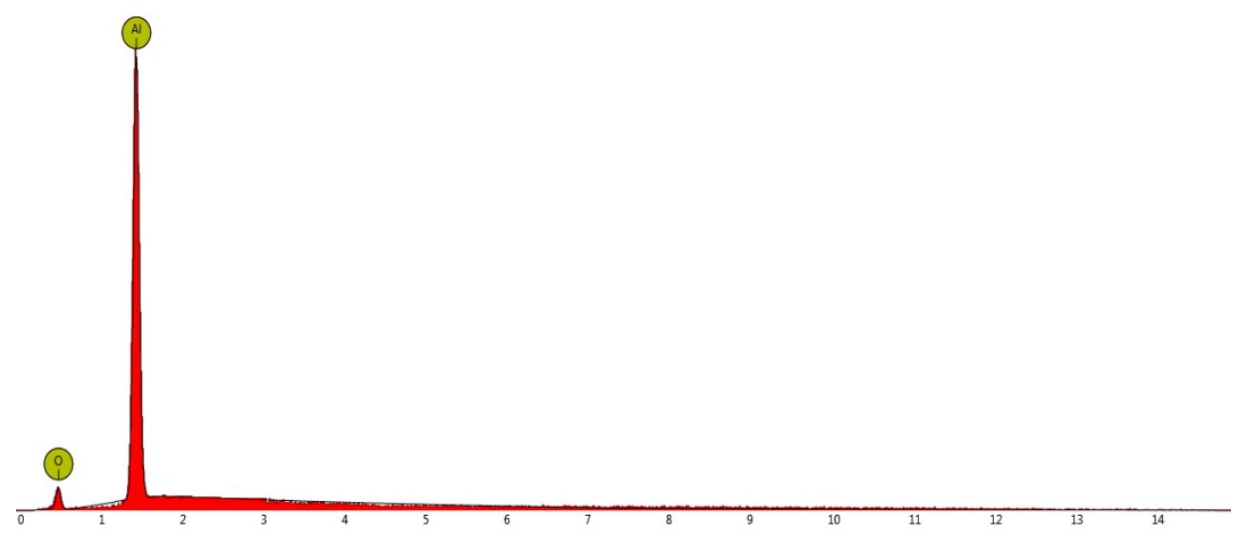

Fig. 4- EDS analysis of the specimen with $5 \% \mathrm{Al}_{2} \mathrm{O}_{3}$ 


\section{2- Microstructure of the material}

The microstructure of the material was examined with optical microscopy. Metallographic samples were prepared up to $1-\mu \mathrm{m}$ surface finish through standard hand polishing. Therefore, grinding was first carried out with 220 up to 5000-grit SiC paper. Subsequently, the polished samples were etched by using a solution mixed by Methanol (25ml), Hydrochloric acid (25ml), Nitric acid (25ml), and Hydrofluoric acid (one drop) and then washed with distilled water and dried. Figs. 5 (a) to (c) show the variation in the microstructure of the MMNCs with different weight percentage of $\mathrm{Al}_{2} \mathrm{O}_{3}$ nanoparticles. The grain size of the material in the specimens was observed ranging from $\sim 10$ to $30 \mu \mathrm{m}$. It was found that the specimens have porosity and agglomeration of nanoparticles. The agglomeration in the specimens increased with the weight percentage of nanoparticles.

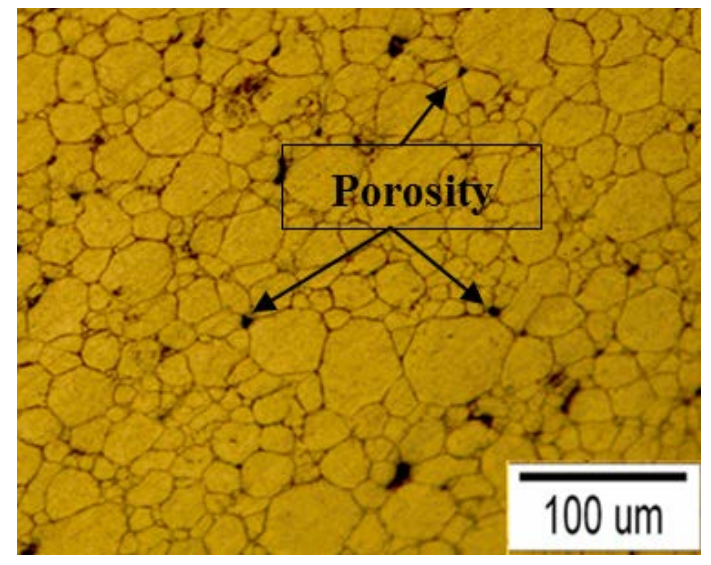

(a)

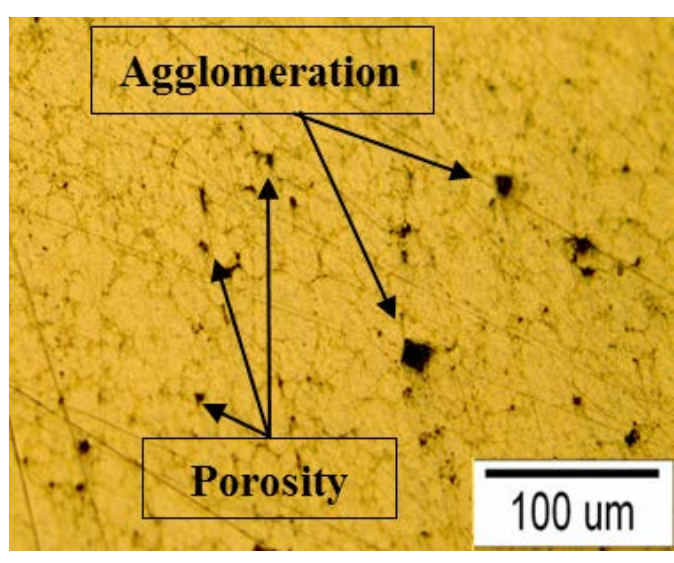

(b)

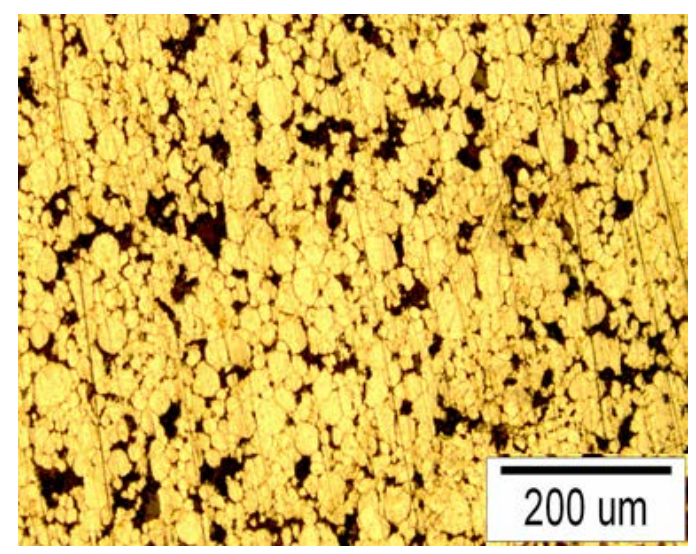

(c)

Fig. 5- Microstructure of the MMNCs with (a) $2.5 \% \mathrm{Al}_{2} \mathrm{O}_{3}$ (b) $7.5 \% \mathrm{Al}_{2} \mathrm{O}_{3}$ (c) $12.5 \% \mathrm{Al}_{2} \mathrm{O}_{3}$ 


\section{3- Deformation behavior of the material}

\subsection{1- Quasi-static compression}

Fig. 6 (a) depicts the specimen without nanoparticles under compression. The specimen was observed to be compressed completely without cracking from the walls and core. However, the specimens reinforced with $\mathrm{Al}_{2} \mathrm{O}_{3}$ nanoparticles showed longitudinal cracks, originating from the external surface of the specimens. Fig. 6(b) shows the compression of the specimen with $10 \% \mathrm{Al}_{2} \mathrm{O}_{3}$ nanoparticles. It can be seen that the material of the specimen detached from the walls and core of the specimens in the compressive deformation. Fig. 6 (c) illustrates the final state of the specimen shown in Fig. 6 (b) loaded in compression. The specimens showed brittle fracture and crushed completely in the compression test.

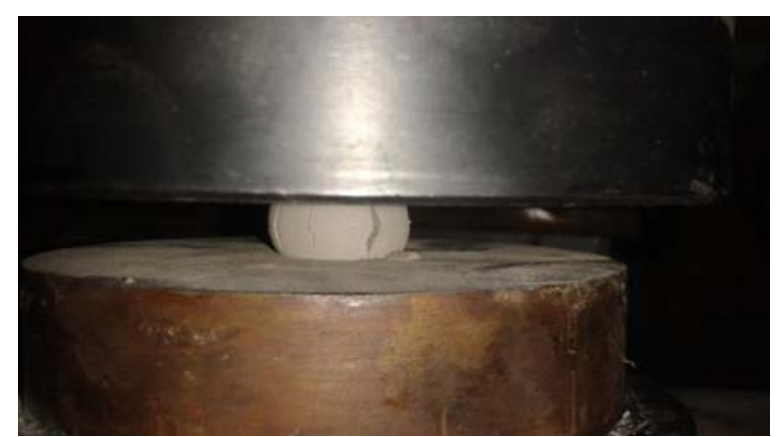

(a)

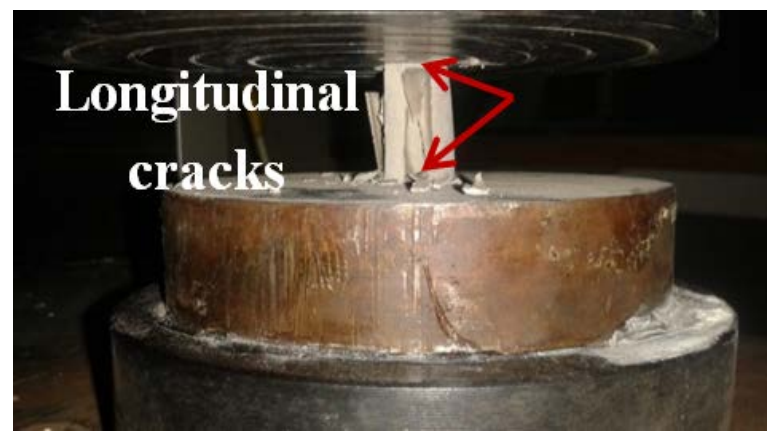

(b)

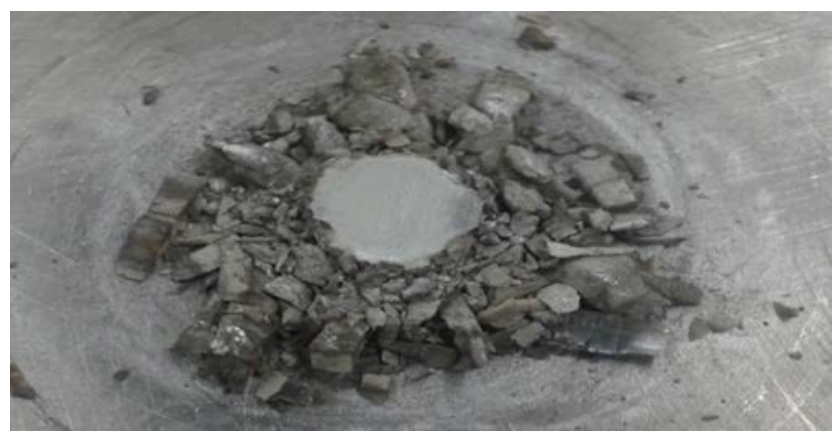

(c)

Fig. 6- Quasi-static compression of the specimens (a) without $\mathrm{Al}_{2} \mathrm{O}_{3}$ (b) with $10 \% \mathrm{Al}_{2} \mathrm{O}_{3}$ (c) final state of the specimen with $10 \% \mathrm{Al}_{2} \mathrm{O}_{3}$

Fig. 7 depicts the quasi-static compressive stress-strain curve of the specimens with different weight percentage of $\mathrm{Al}_{2} \mathrm{O}_{3}$ nanoparticles. The stress-strain curve of the specimens exhibited three different stages of deformation. Initially, the stiff and elastic deformation was observed that strain increased linearly up to the yield stress. The specimens with nanoparticles were found to have a steeper elastic part in the deformation than the pure aluminum specimen. The plastic part of deformation initially showed a stress plateau where the strain increased continuously without an increase in the stress. The stress plateau region was found to be followed by a sharp increase in stress without an increase in the strain. 
The stress plateau in the first part of the plastic deformation can be attributed to the progressive plastic deformation and the fracture of $\mathrm{Al}_{2} \mathrm{O}_{3}$ nanoparticles. The effect of plateau stress was not observed in the specimens with a lower weight percentage of nanoparticles. The sharp increase in the stress followed by plateau stress can be attributed to the densification of the specimens in compression. The specimens without plateau stress showed densification in the initial stage of the plastic deformation. The lower yield stress of the specimens with a higher weight percentage of $\mathrm{Al}_{2} \mathrm{O}_{3}$ nanoparticles can be attributed to the agglomeration of particles, which produces the stress concentration in the particle cluster zones [3, 11].

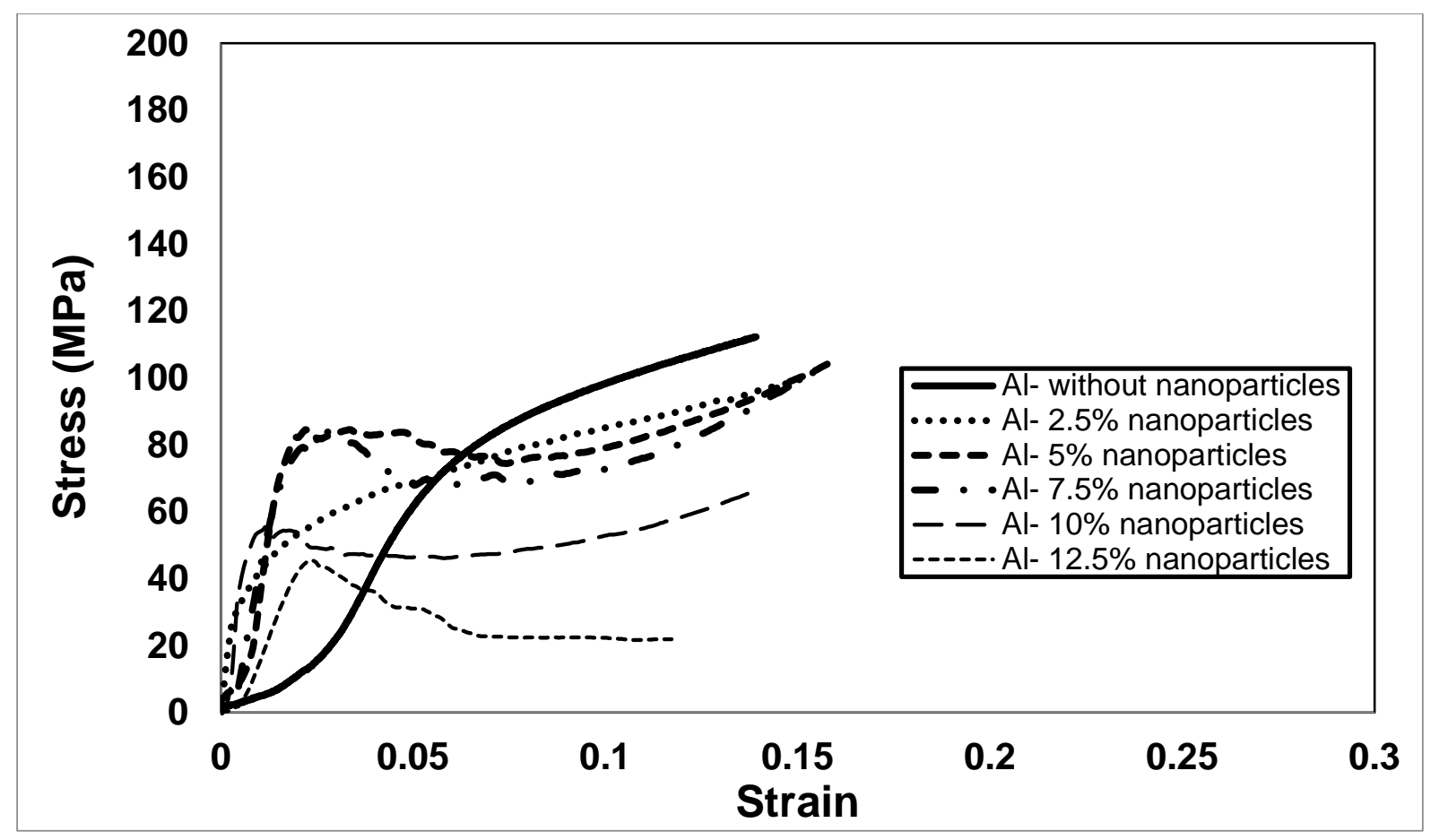

Fig. 7- Quasi-static stress-strain curve of the specimens with different weight percentage of nanoparticles in aluminium matrix

\subsection{2- Energy absorption in quasi-static compression}

The area under the stress-strain curve was used to calculate the energy absorbed by the specimens in deformation. Fig. 8 shows the variation in energy absorbed and yield stress of specimens with their weight percentage of nanoparticles. It can be seen that the energy absorption and yield stress of specimens initially increased with the weight percentage of the nanoparticles. It was observed that the specimens with 5\% nanoparticles possess the highest energy absorption and yield stress. Further addition of $\mathrm{Al}_{2} \mathrm{O}_{3}$ nanoparticles to the specimens resulted in a reduction in the energy absorption and yield stress of the material. However, the reduction in energy absorption was noticeably higher than the reduction in yield stress. It can be demonstrated that $5 \% \mathrm{Al}_{2} \mathrm{O}_{3}$ in an aluminum matrix contributes to the optimal weight percentage of the nanoparticles, leading to markedly higher material properties of the composites. Further addition of nanoparticles increases the agglomeration in the material. The high cohesive energy of agglomerations and clusters in the specimens cause brittleness, leading 
to a reduction in the energy absorption capacity of the material. The excess of nanoparticles does not significantly affect the stiffness and yield stress of the material.

It can be indicated that the matrix and strengthening particles deform elastically up to the yield point first. In the plastic deformation phase, the nanoparticles deform and yield with loading initially. Subsequently, the progressive failure of widespread nanoparticles culminates in a stress plateau in the deformation. The material absorbs deformation strain energy in the plateau stress state. The failure of nanoparticles follows by transferring of loading to the matrix and results in a sharp increase in stress without further increase in the strain and energy absorption [12, 28-29]. Multiple long cracks originating from the surface and core of the specimens can be observed, which finally result in the complete crushing of the samples.

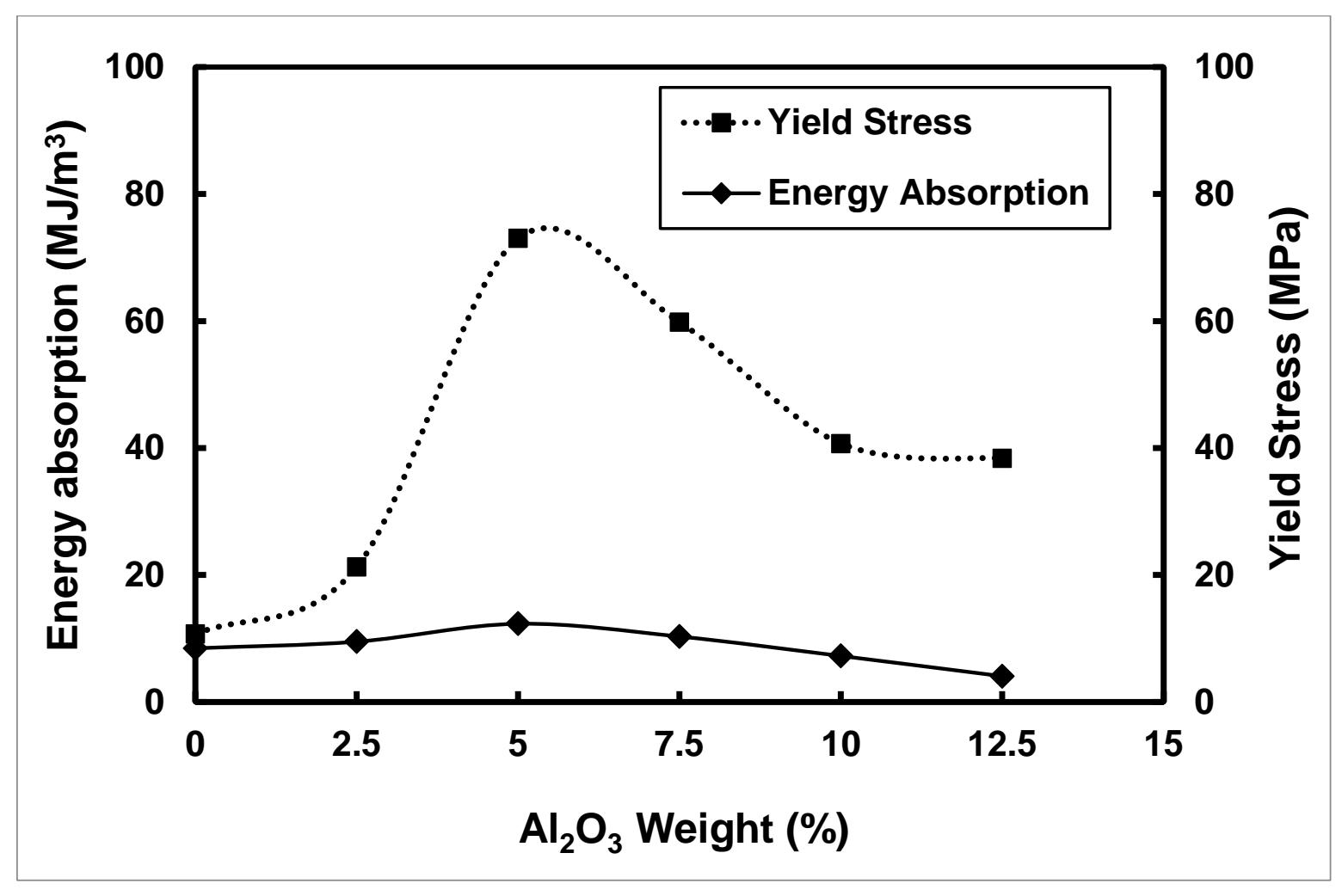

Fig. 8- Variation in energy absorption capacity and yield stress of the specimens with different weight percentage of $\mathrm{Al}_{2} \mathrm{O}_{3}$ nanoparticles

Fig. 9 (a) depicts the fracture surface of the specimen without $\mathrm{Al}_{2} \mathrm{O}_{3}$ nanoparticles. The surface showed ductile failure with multiple narrow cracks moving along the grain boundaries. The fracture surface examination inferred that the coalescence of micro-cavities led to nucleation and growth of cracks. The surface of specimens with $\mathrm{Al}_{2} \mathrm{O}_{3}$ nanoparticles showed various large cracks. Fig. 9 (b) illustrates the fracture surface of the specimen with $2.5 \% \mathrm{Al}_{2} \mathrm{O}_{3}$ nanoparticles. The fracture surface was found to have a higher density of deformed regions. Fig. 9 (c) and (d) show the fracture surface of specimens with 7.5 and $12.5 \%$ nanoparticles. It can be seen that the fracture surface of specimens have various micro-cracks with crack branching and crack arresting. It can be said that the specimens with nanoparticles fracture globally with several localized fractured areas. 


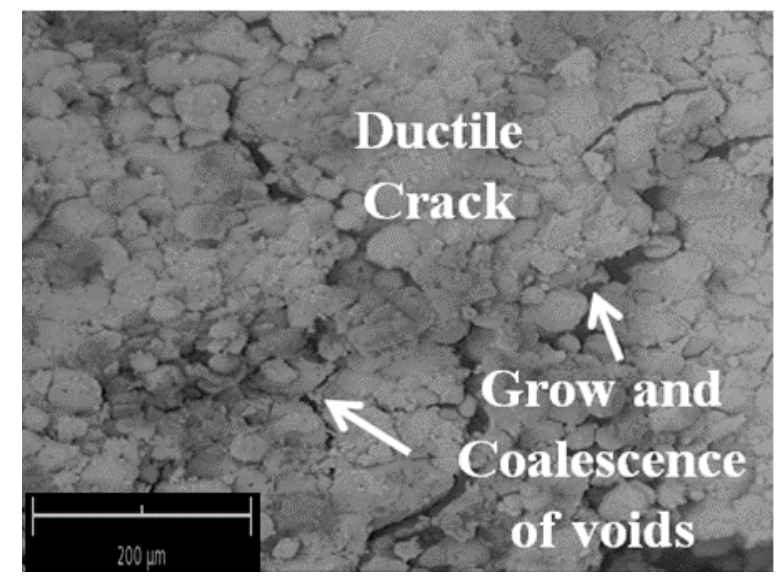

(a)

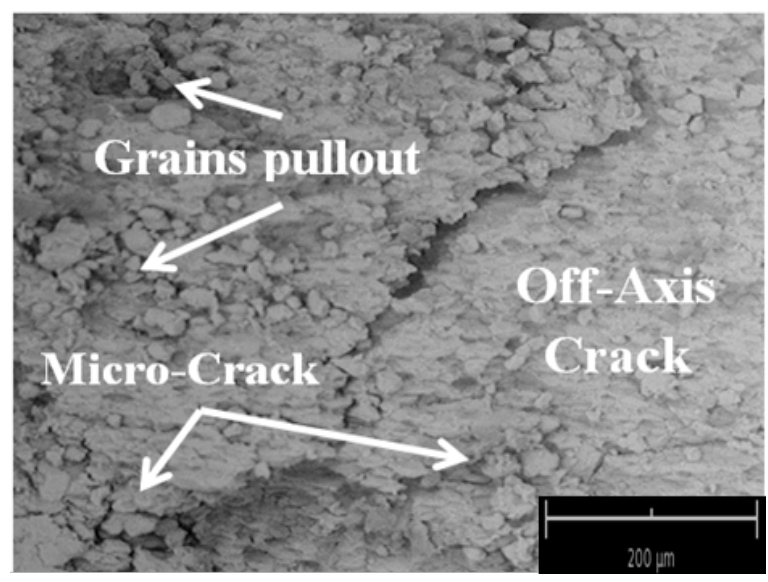

(c)

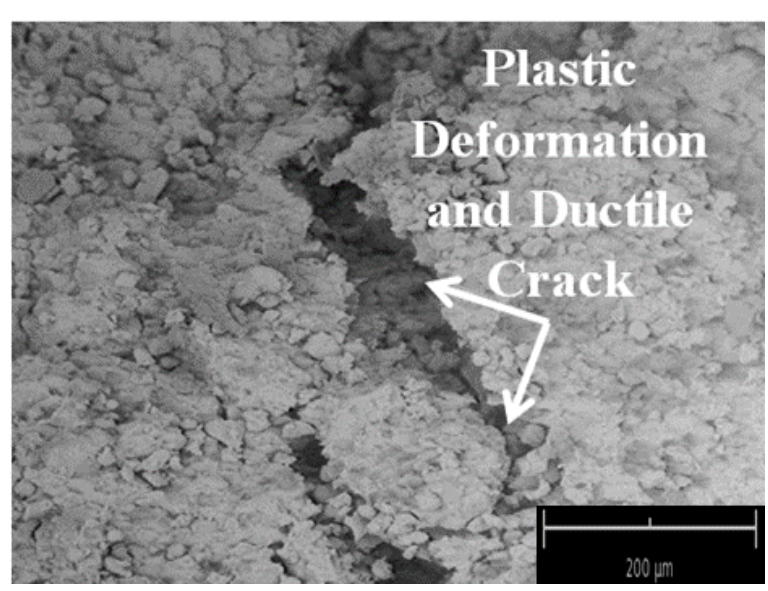

(b)

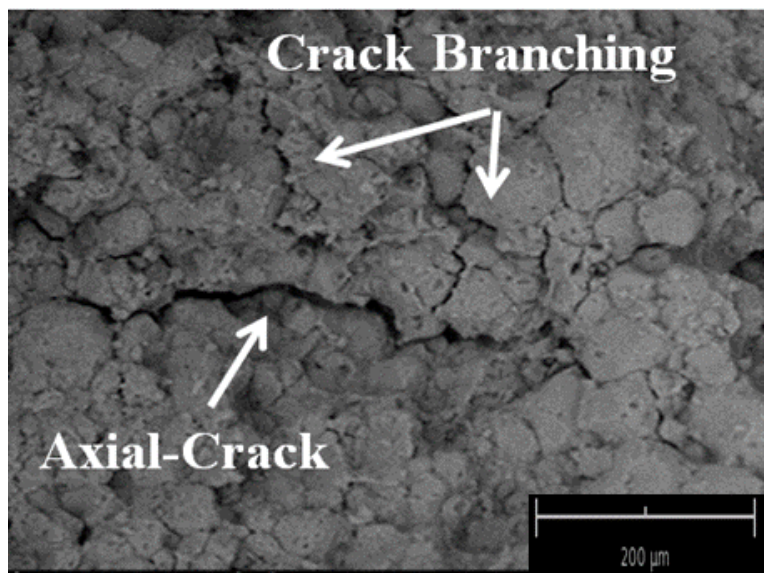

(d)

Fig. 9- SEM micrographs of the fracture specimens after quasi-static loading (a) $\mathrm{Al}-0 \% \mathrm{Al}_{2} \mathrm{O}_{3}$, (b) $\mathrm{Al}-2.5 \% \mathrm{Al}_{2} \mathrm{O}_{3}$ (c) $\mathrm{Al}-7.5 \% \mathrm{Al}_{2} \mathrm{O}_{3}$, (d) $\mathrm{Al}-12.5 \% \mathrm{Al}_{2} \mathrm{O}_{3}$

\subsection{3- High strain rate compression}

The dynamic compressive stress-strain deformation behavior of specimens was obtained from SHPB tests at different high strain rates. Three strain rates including 700, 1400 and $3000 \mathrm{~s}^{-1}$ were used. Figs. 10 (a), (b), and (c) show the variation in compressive stress-strain deformation of specimens with strain rate. The deformation of specimens showed longer elastic and plastic deformation in the stress-strain curve as compared to their quasi-static deformation. The compressive strength and the fracture strain at higher strain rates were found to be markedly higher than those of the quasi-static compression. 


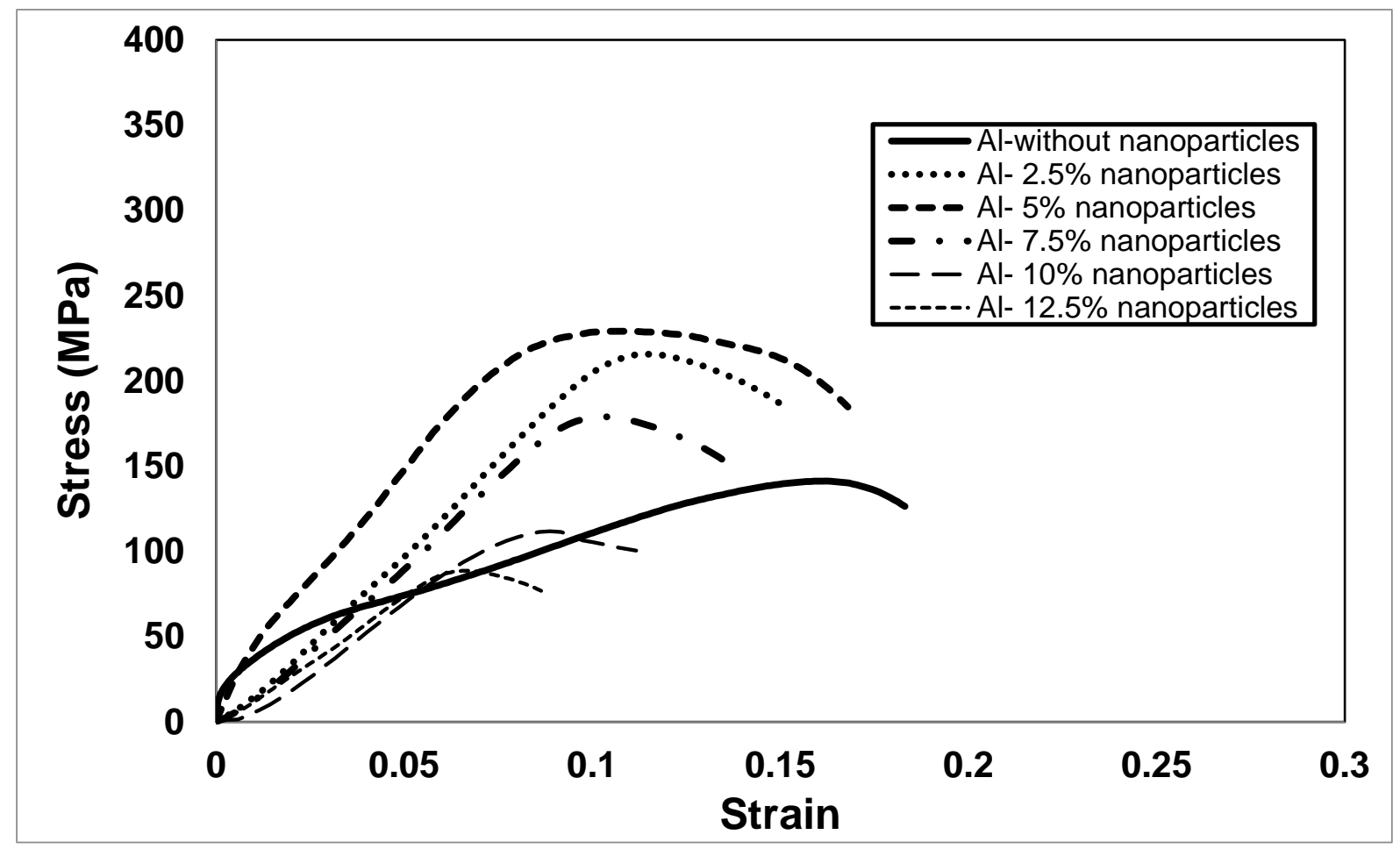

(a)

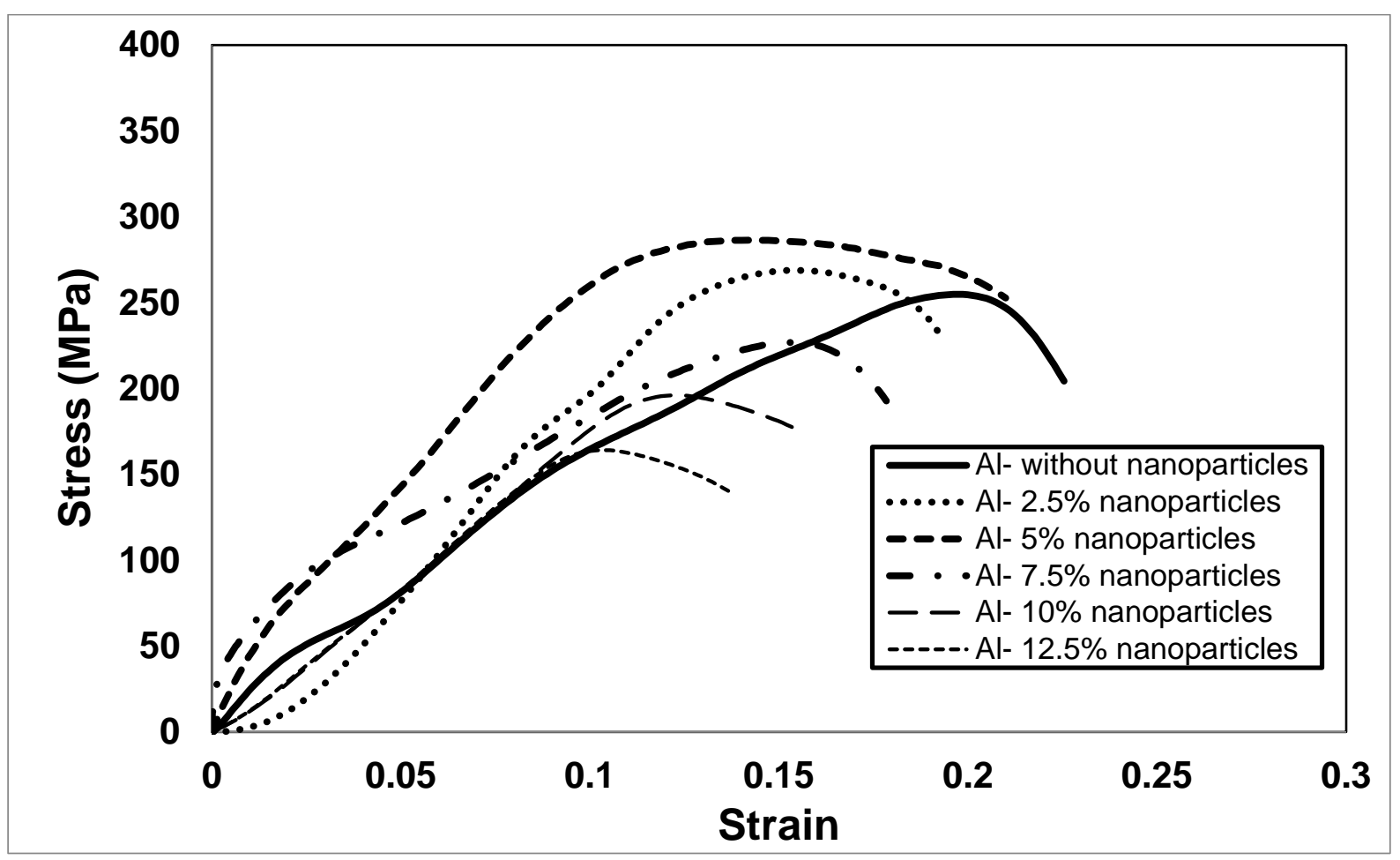

(b) 


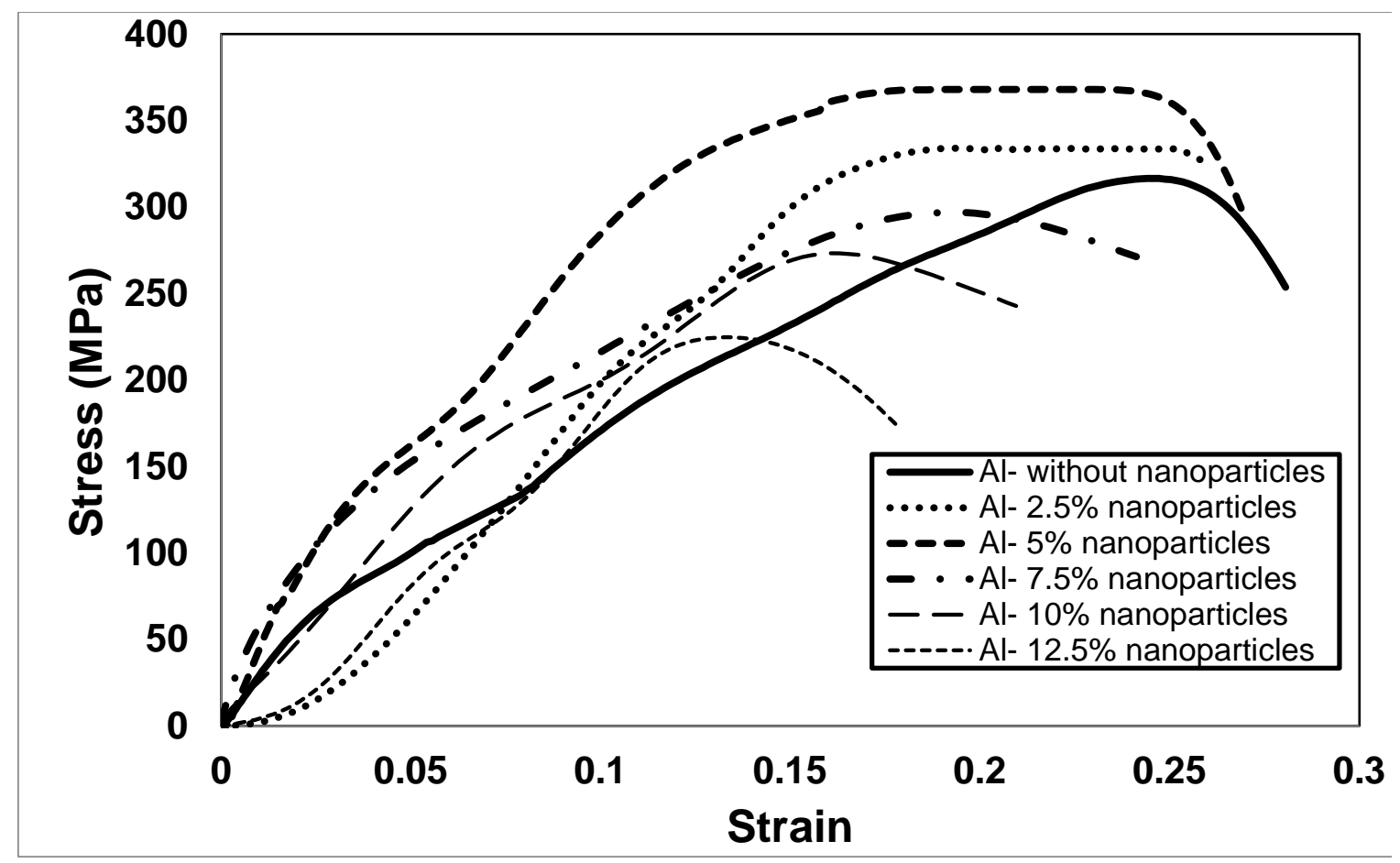

(c)

Fig. 10- Dynamic stress-strain curve of the specimens with different weight percentage of $\mathrm{Al}_{2} \mathrm{O}_{3}$ nanoparticles at (a) $700 s^{-1}$ (b) $1400 s^{-1}$ (b) $3000 s^{-1}$

Fig. 11 exhibits the variation in the energy absorption of the specimens with a different weight percentage of reinforcement. The deformation energy absorbed by the specimens was found to be increasing linearly with strain rate. The highest strain energy absorption is associated with the specimens deformed at the highest strain rate. The energy absorbed was found to vary with the weight percentage of nanoparticles in the specimen. The energy absorption of the specimens rose linearly as the percentage of nanoparticles increased. The energy absorption reached to the maximum amount in the specimens reinforced with $5 \% \mathrm{Al}_{2} \mathrm{O}_{3}$ nanoparticles. Further addition of nanoparticles in the specimens linearly decreased their energy absorption capacity. Similar to the quasi-static compression, a $5 \% \mathrm{Al}_{2} \mathrm{O}_{3}$ nanoparticles was the optimal weight percentage of nanoparticles in the material, leading to the highest energy absorption capacity in high strain rate deformation. However, the properties of the material were found to be significantly higher at higher strain rates. This reveals that the quasi-static compression of material with an optimal weight percentage of nanoparticles shows conservative characteristics of the material. The investigation of the high strain rate deformation characteristics demonstrates the full potential of the material for energy absorption. 


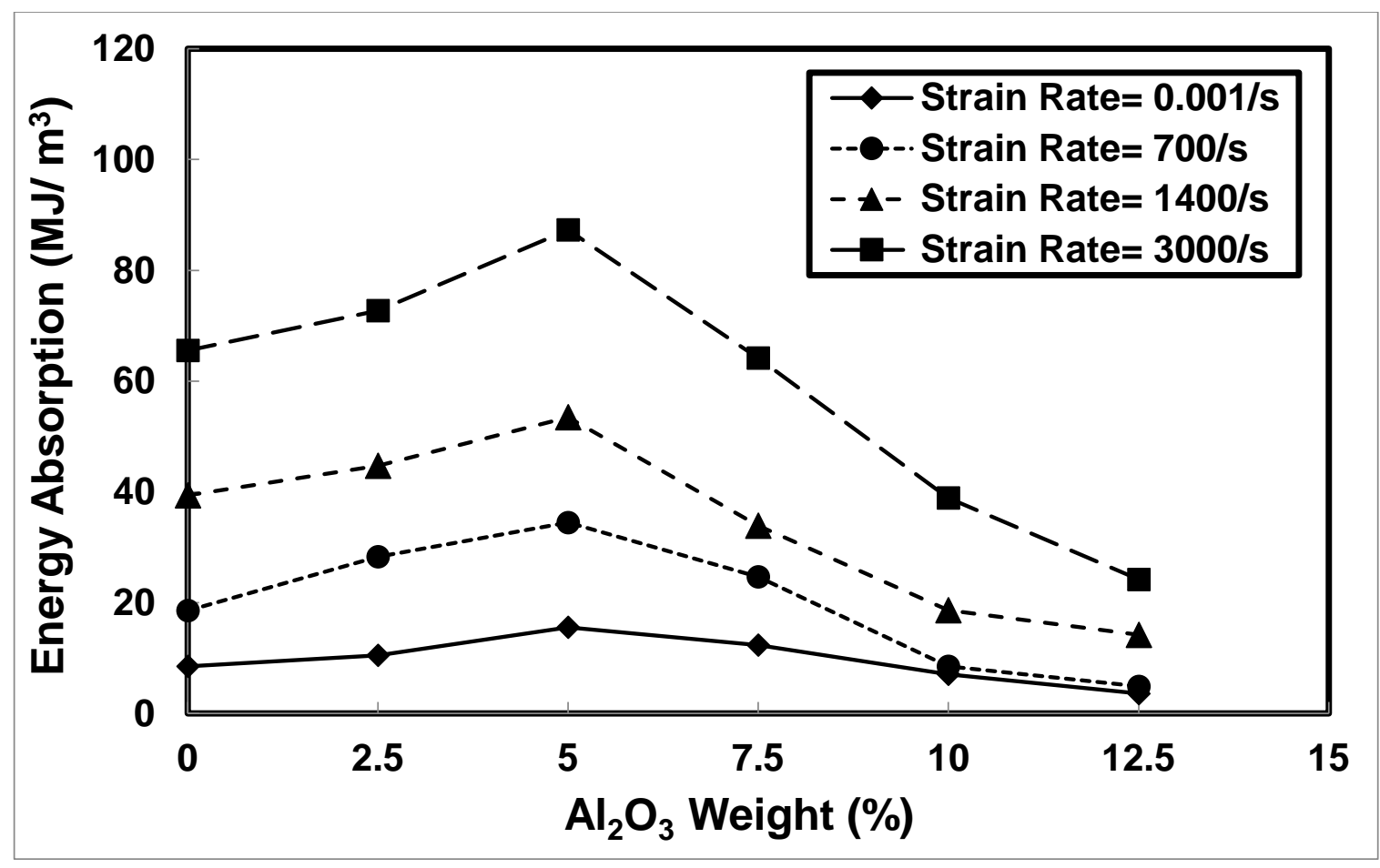

Fig. 11- Energy absorption capacity at different strain rates in the specimens with different weight percentage of $\mathrm{Al}_{2} \mathrm{O}_{3}$ nanoparticles

\subsection{4- Energy absorption in high strain rate compression}

The variation in the energy absorption capacity of the specimens with strain rate was found to be higher in those with a higher weight percentage of nanoparticles. It could be seen that the variation in energy absorption was substantial in the specimens with an optimal weight percentage of nanoparticles. This showed a higher strain rate sensitivity of material with an optimal weight percentage of nanoparticles. However, the material with a higher weight percentage of nanoparticles exhibited an extremely lower strain rate sensitivity. It can be said that the energy absorption characteristics of $\mathrm{Al}_{2} \mathrm{O}_{3}$ based MMCs can be significantly enhanced when optimal weight percentage of nanoparticles is used.

The fracture surfaces of the specimens subjected to higher strain rates in SHPB tests showed that the specimens were broken in several pieces. The specimens loaded in compression at $3000 \mathrm{~s}^{-1}$ strain rate was found to be completely crushed. Therefore, the fracture surfaces of specimens compressed at 700 and $1400 \mathrm{~s}^{-1}$ have been used in the analysis. Fig. 12 (a) shows the fracture surface of the specimen without nanoparticle strengthening. The surface was found to have smooth ductile cracks with partial debonding. The cracks were observed along the grain boundaries with smooth paths, which showed the ductile flow of the material.

Fig. 12 (b) to (d) illustrates the fracture surface of the specimens with nanoparticles. The fracture surface revealed the brittle fracture with several macro/micro-cracks with crack branching and arrested cracks. It was concluded that the addition of nanoparticles results in a brittle fracture. Failure mechanisms of studied MMCs involved particles pullout, multiple 
micro-cracks, and cracking from agglomerated regions, particularly in case of specimens with the high percentage of nano-ceramic particles.

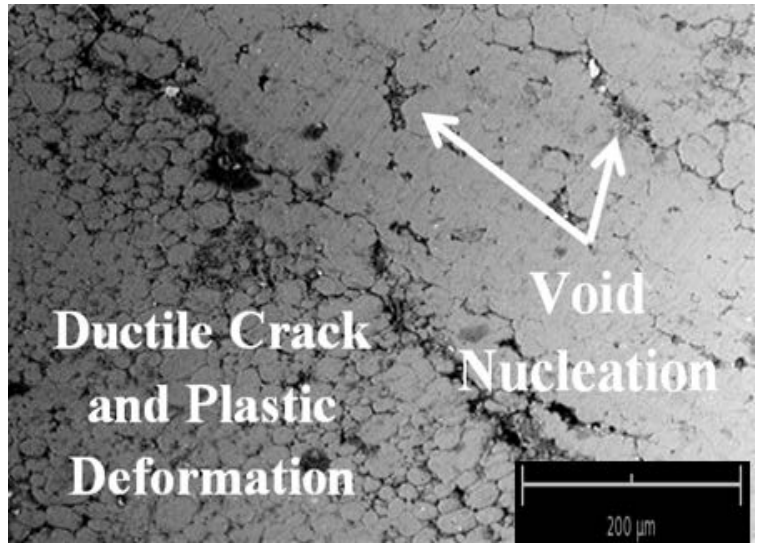

(a)

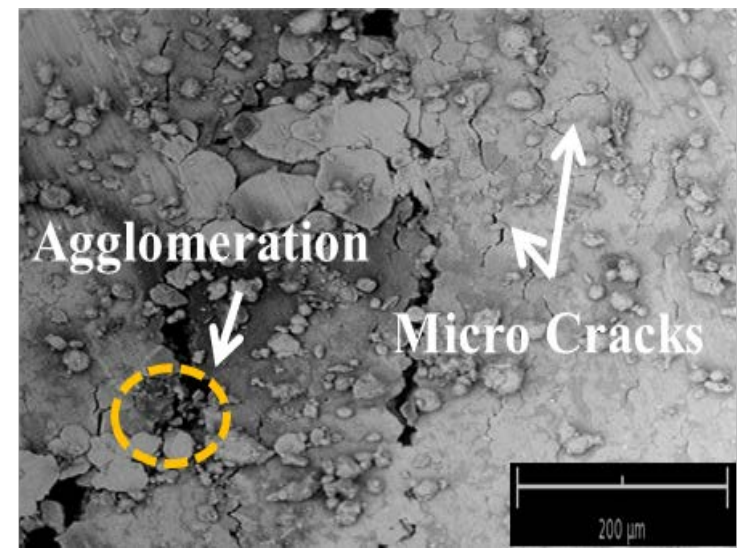

(c)

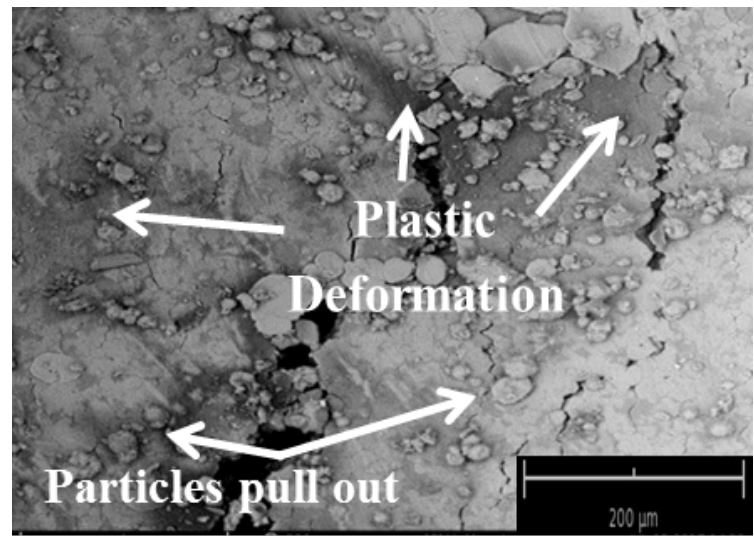

(b)

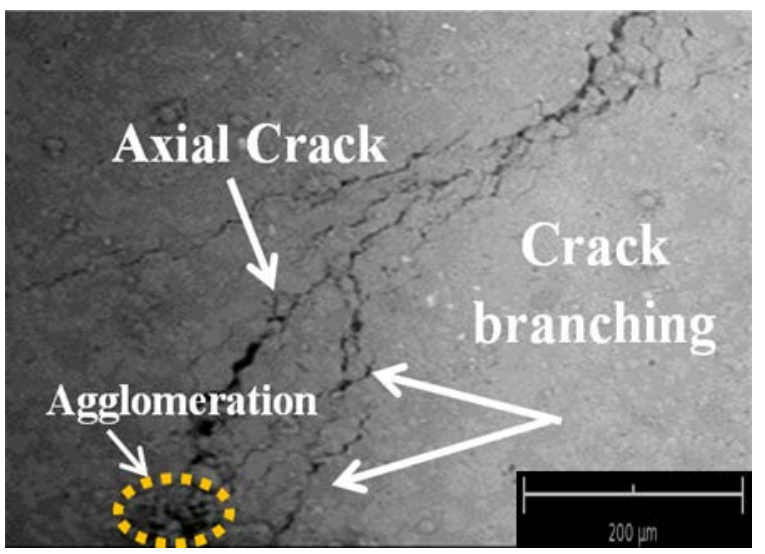

(d)

Fig. 12- Fracture surface of the specimens after SHPB testing at $1400 \mathrm{~s}^{-1}$ strain rate (a) the specimen without nanoparticles (b) the specimen with $5 \% \mathrm{Al}_{2} \mathrm{O}_{3}$ showing plastic deformation (c) the specimen with $7.5 \% \mathrm{Al}_{2} \mathrm{O}_{3}$ showing agglomeration and micro-cracks (d) the specimen with $12.5 \% \mathrm{Al}_{2} \mathrm{O}_{3}$ showing multiple cracks

\section{4- Strain rate sensitivity}

The quasi-static and dynamic compression of $\mathrm{Al}-\mathrm{Al}_{2} \mathrm{O}_{3}$ composites showed their potential in engineering applications, including energy absorption requirements. The non-linear plastic deformation behavior of the specimens in the compression warrants detailed investigation of energy absorption capacity at different deformation strains. The energy absorption capacity just represents the area under the stress-strain curve without reflecting the behavior of composites at specific strains. Fig. 13 shows the effect of strain rate on the hardening behavior of 5 W.t \% nanocomposite sample. The strain hardening exponent $n$ can be calculated by Eq. (4) [30]: 


$$
n=\frac{d \log \sigma_{t}}{d \log \varepsilon_{t}}
$$

where $\sigma_{t}$ and $\varepsilon_{t}$ represent true stress and true strain, respectively. Comparing the curves shown in Fig. 13, it can be seen that in the case of the quasi-static loading, the true stress-true strain curve increases almost linearly with a slope of 0.834 , which represents the strain hardening exponent. As the strain rate increases, the linear relationship can be observed only in a certain region of the curves. In other words, at high strain rate loading, the heat generation during dynamic compression causes matrix softening that results in a slight decrease in the hardening exponent.

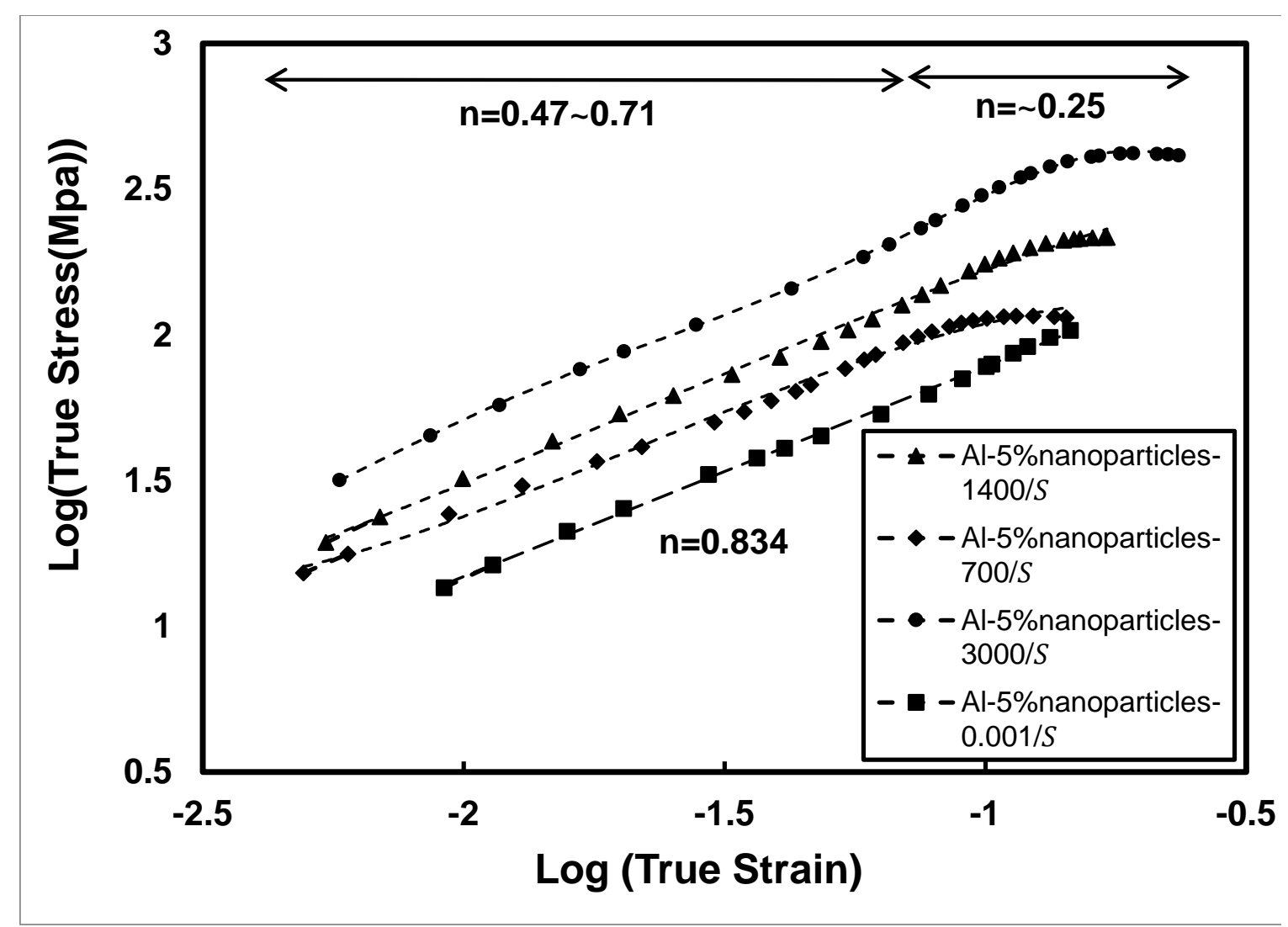

Fig 13. Effect of strain rate on the hardening behavior of $5 \mathrm{Wt} \%$ nanocomposite sample

In order to provide a better explanation, Table 2 shows the variation in strain hardening exponent of the material with deformation strain. The strain hardening exponent was calculated in three deformation strain intervals. The initial hardening exponent of the material up to $6 \%$ strain found to be similar irrespective of the deformation strain rates. However, the strain hardening exponent increased in 6 to 12\% deformation strain interval. The hardening exponent was higher for the specimens deformed with higher strain rate. The strain hardening exponent of the material was found to be decreased in 12 to $22 \%$ deformation strain interval. This revealed that the initial deformation of the material is not dependent on the deformation strain rate and the material shows similar hardening behavior. The hardening of the material improves in the middle part of the deformation (i.e. 6 to $12 \%$ strain interval). Additionally, with the 
increase in strain rate, hardening exponent has a tendency to increase. The material becomes soft in the final part of the deformation and shows lower strain hardening up to fracture.

Table 2- Variation of the strain hardening exponent of $5 \% \mathrm{Al}_{2} \mathrm{O}_{3}$ specimen with strain rate

\begin{tabular}{|c|c|c|c|c|}
\hline \multirow{2}{*}{ S. No. } & \multirow{2}{*}{ Strain Rate $\left(\boldsymbol{s}^{\mathbf{- 1}}\right)$} & \multicolumn{3}{|c|}{ Deformation Strain } \\
\cline { 3 - 5 } & & Up to 6\% & $\mathbf{6}$ to 12\% & $\mathbf{1 2 \text { to 22\% }}$ \\
\hline 1 & 700 & 0.47 & 0.51 & Not-Available \\
\hline 2 & 1400 & 0.48 & 0.64 & 0.23 \\
\hline 3 & 3000 & 0.49 & 0.7 & 0.25 \\
\hline
\end{tabular}

The strain rate sensitivity factor $R$ was calculated for the specimens with different weight percentage of nanoparticles at different deformations, from Eq. (5).

$$
R=\frac{\ln \left(\sigma_{d} / \sigma_{q}\right)}{\ln \left(\dot{\varepsilon}_{d} / \dot{\varepsilon}_{q}\right)}
$$

where $\sigma_{d}$ and $\sigma_{q}$ are the flow stress at high and quasi-static strain rate which are denoted by $\dot{\varepsilon}_{d}$ and $\dot{\varepsilon}_{q}$, respectively. Fig. 14 shows the variation in strain rate sensitivity factor $R$ with total strain at different strain rates for the material with an optimal weight percentage of nanoparticles. The strain rate sensitivity was found to be higher at higher strain rates. In the initial stage of deformation, the strain rate sensitivity factor increased and reached the highest value at $10 \%$ strain. The difference in the strain rate sensitivity factor for different rates was similar up to this deformation strain. However, the difference between the strain rate sensitivity increased with further increase in the deformation strain. The specimens deformed at lower strain rates showed lower sensitivity factor by comparison to those deformed at higher strain rates. This demonstrated that the deformation behavior of the specimens with an optimal percentage of nanoparticles varies significantly with strain rate. The energy absorption capacity of the material is significantly higher at higher strain rates. Simply put, the $\mathrm{Al}_{2} \mathrm{O}_{3}$ nanoparticles based aluminum MMCs show the potential to be functional in deformation at high strain rates for the purpose of energy absorption. 


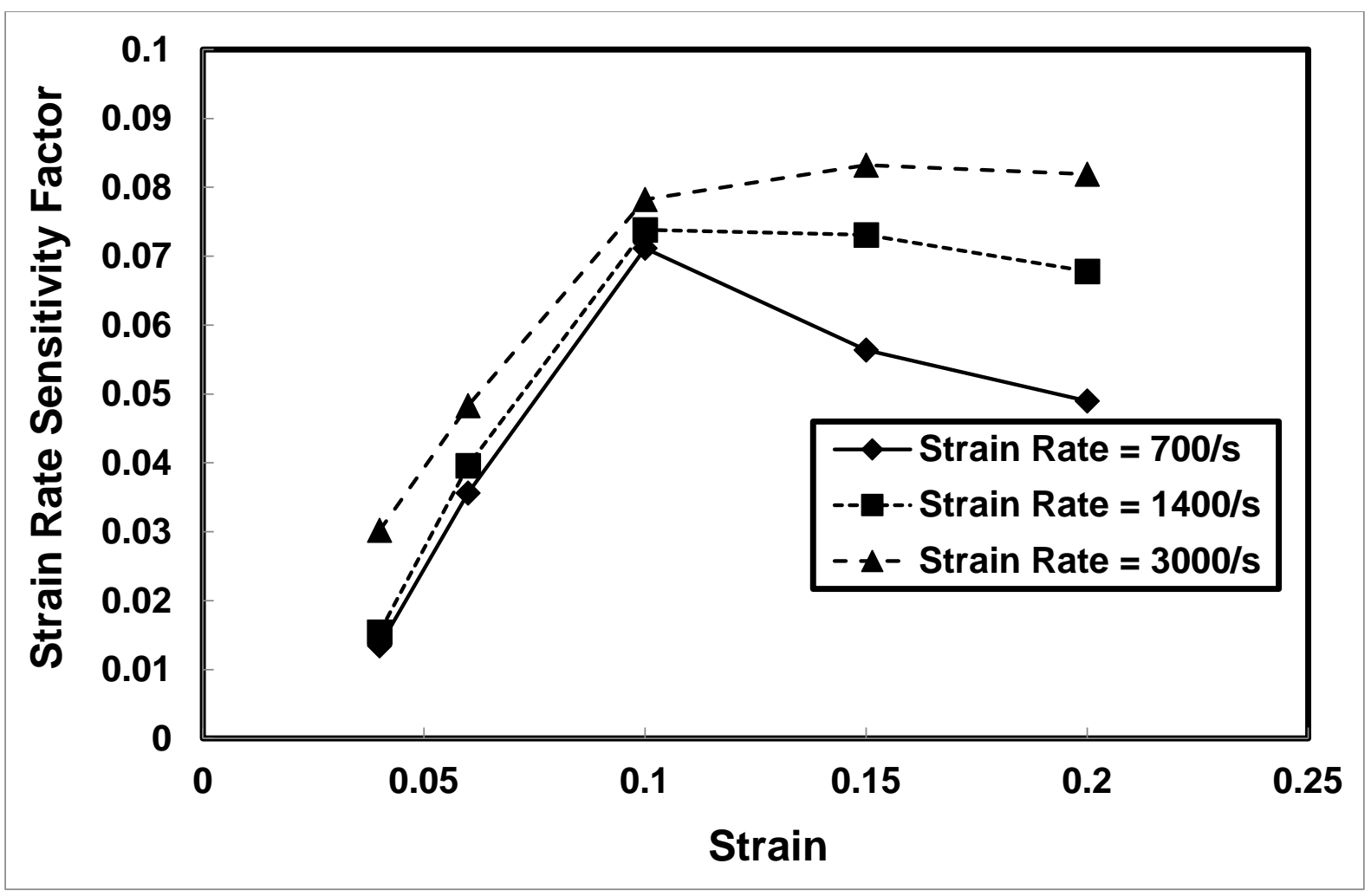

Fig. 14- Variation of the strain rate sensitivity factor at different strains for the $\mathbf{5 \%}$ nanoparticle specimen; the figure shows data from different strain rates

\section{Conclusions}

The quasi-static and high strain rate deformation behavior of Aluminum-based Metal Matrix composite with $\mathrm{Al}_{2} \mathrm{O}_{3}$ nanoparticles was investigated and the following conclusions can be drawn from this study:

1- The variation in the deformation characteristics of the material with different weight percentages of $\mathrm{Al}_{2} \mathrm{O}_{3}$ nanoparticles revealed the strain rate sensitive behavior of the present MMNCs.

2- It was concluded that the addition of optimal weight percentage of nanoparticles (5 wt. \% in this study) increases significantly the compressive strength and energy absorption capacity of the material.

3- It can be demonstrated that the material absorbs significantly higher energy in the high strain rate deformation. Besides, the optimal weight percentage of nanoparticles contributes to the considerable higher energy absorption characteristics in all strain rates.

4- The addition of nanoparticles beyond the optimal weight percentage reduces the energy absorption capacity and strain rate sensitivity of the material.

5- The $\mathrm{Al}_{2} \mathrm{O}_{3}$ nanoparticles based aluminum MMCs can be highly beneficial to energy absorption in high strain rate loading. 


\section{References}

[1] K. Shirvanimoghaddam, H. Khayyam, H. Abdizadeh, M. K. Akbari, A. Pakseresht, E. Ghasali, M. Naebe, Boron carbide reinforced aluminium matrix composite: Physical, mechanical characterization and mathematical modelling, Materials Science and Engineering: A, Vol. 658, pp. 135-149, 2016.

[2] M. K. Akbari, H. Baharvandi, O. Mirzaee, Fabrication of nano-sized Al2O3 reinforced casting aluminum composite focusing on preparation process of reinforcement powders and evaluation of its properties, Composites Part B: Engineering, Vol. 55, pp. 426-432, 2013.

[3] P. Gudlur, A. Forness, J. Lentz, M. Radovic, A. Muliana, Thermal and mechanical properties of $\mathrm{Al} / \mathrm{Al} 2 \mathrm{O} 3$ composites at elevated temperatures, Materials Science and Engineering: A, Vol. 531, pp. 18-27, 2012.

[4] L. Kunčická, T. C. Lowe, C. F. Davis, R. Kocich, M. Pohludka, Synthesis of an $\mathrm{Al} / \mathrm{Al} 2 \mathrm{O} 3$ composite by severe plastic deformation, Materials Science and Engineering: A, Vol. 646, pp. 234-241, 2015.

[5] Y. Yang, Z. Zhang, X. Zhang, Processing map of Al2O3 particulate reinforced Al alloy matrix composites, Materials Science and Engineering: A, Vol. 558, pp. 112-118, 2012.

[6] M. Balog, F. Simancik, M. Walcher, W. Rajner, C. Poletti, Extruded Al-Al2O3 composites formed in situ during consolidation of ultrafine Al powders: Effect of the powder surface area, Materials Science and Engineering: A, Vol. 529, pp. 131-137, 2011.

[7] A. Yonezu, B. Xu, X. Chen, Indentation induced lateral crack in ceramics with surface hardening, Materials Science and Engineering: A, Vol. 507, No. 1-2, pp. 226-235, 2009.

[8] B.-f. Luan, R.-s. Qiu, C.-h. Li, X.-f. Yang, Z.-q. Li, D. Zhang, L. Qing, Hot deformation and processing maps of Al2O3/Al composites fabricated by flake powder metallurgy, Transactions of Nonferrous Metals Society of China, Vol. 25, No. 4, pp. 1056-1063, 2015.

[9] M. Zabihi, M. R. Toroghinejad, A. Shafyei, Application of powder metallurgy and hot rolling processes for manufacturing aluminum/alumina composite strips, Materials Science and Engineering: A, Vol. 560, pp. 567-574, 2013.

[10] M. Rahimian, N. Parvin, N. Ehsani, The effect of production parameters on microstructure and wear resistance of powder metallurgy Al-Al2O3 composite, Materials \& Design, Vol. 32, No. 2, pp. 1031-1038, 2011.

[11] M. Rahimian, N. Ehsani, N. Parvin, H. reza Baharvandi, The effect of particle size, sintering temperature and sintering time on the properties of $\mathrm{Al}-\mathrm{Al} 2 \mathrm{O} 3$ composites, made by powder metallurgy, Journal of Materials Processing Technology, Vol. 209, No. 14, pp. 5387-5393, 2009.

[12] T. Christman, A. Needleman, S. Suresh, An experimental and numerical study of deformation in metal-ceramic composites, Acta Metallurgica, Vol. 37, No. 11, pp. 3029-3050, 1989.

[13] D. Liu, M. Manoharan, J. Lewandowski, Effects of microstructure of the behavior of an aluminum alloy and an aluminum matrix composite tested under low levels of superimposed hydrostatic pressure, Metallurgical Transactions A, Vol. 20, No. 11, pp. 2409-2417, 1989. 
[14] J. Yang, S. Pickard, C. Cady, A. Evans, R. Mehrabian, The stress/strain behavior of aluminum matrix composites with discontinuous reinforcements, Acta metallurgica et materialia, Vol. 39, No. 8, pp. 1863-1869, 1991.

[15] C.-W. Nan, D. Clarke, The influence of particle size and particle fracture on the elastic/plastic deformation of metal matrix composites, Acta materialia, Vol. 44, No. 9, pp. 3801-3811, 1996.

[16] S. Chen, T. Wang, Size effects in the particle-reinforced metal-matrix composites, Acta Mechanica, Vol. 157, No. 1-4, pp. 113-127, 2002.

[17] M. Kök, Abrasive wear of Al2O3 particle reinforced 2024 aluminium alloy composites fabricated by vortex method, Composites Part A: applied science and manufacturing, Vol. 37, No. 3, pp. 457-464, 2006.

[18] J. Harding, M. Taya, B. Derby, S. Pickend, Proceedings of the ICCM-6/ECCM-2 Applied Science, pp. 2.224-2.233, 1987.

[19] S. Yadav, D. Chichili, K. Ramesh, The mechanical response of a 6061-T6 A1/A12O3 metal matrix composite at high rates of deformation, Acta Metallurgica et Materialia, Vol. 43, No. 12, pp. 4453-4464, 1995.

[20] D. Chichili, K. Ramesh, Dynamic failure mechanisms in a 6061-T6 Al/Al2O3 metalmatrix composite, International journal of solids and structures, Vol. 32, No. 17-18, pp. 2609-2626, 1995.

[21] C. San Marchi, F. Cao, M. Kouzeli, A. Mortensen, Quasistatic and dynamic compression of aluminum-oxide particle reinforced pure aluminum, Materials Science and Engineering: A, Vol. 337, No. 1-2, pp. 202-211, 2002.

[22] J. Shen, W. Yin, Q. Wei, Y. Li, J. Liu, L. An, Effect of ceramic nanoparticle reinforcements on the quasistatic and dynamic mechanical properties of magnesiumbased metal matrix composites, Journal of Materials Research, Vol. 28, No. 13, pp. 1835-1852, 2013.

[23] X. Jing, W. S. Dong, Dynamic Response of Magnesium Alloy and its Nanocomposite under High Strain Rate Compressive Loading, in Proceeding of, Trans Tech Publ, pp. 20-25.

[24] Y. Chen, Y. Guo, M. Gupta, V. Shim, A study of the dynamic compressive response of AZ31/Al2O3 nanocomposites and the influence of nanoparticles, International Journal of Impact Engineering, Vol. 89, pp. 114-123, 2016.

[25] K. T. Ramesh, High rates and impact experiments, in: Springer handbook of experimental solid mechanics, Eds., pp. 929-960: Springer, 2008.

[26] W. W. Chen, B. Song, Split Hopkinson (Kolsky) bar: design, testing and applications: Springer Science \& Business Media, 2010.

[27] M. A. Kaiser, Advancements in the split Hopkinson bar test, Thesis, Virginia Tech, 1998.

[28] A. Sanaty-Zadeh, Comparison between current models for the strength of particulatereinforced metal matrix nanocomposites with emphasis on consideration of Hall-Petch effect, Materials Science and Engineering: A, Vol. 531, pp. 112-118, 2012.

[29] T. Christman, A. Needleman, S. Nutt, S. Suresh, On microstructural evolution and micromechanical modelling of deformation of a whisker-reinforced metal-matrix composite, Materials Science and Engineering: A, Vol. 107, pp. 49-61, 1989.

[30] J. Xiao, D. W. Shu, X. Wang, Effect of strain rate and temperature on the mechanical behavior of magnesium nanocomposites, International Journal of Mechanical Sciences, Vol. 89, pp. 381-390, 2014. 